\title{
Comparative study of ocular manifestations of HIV infection at a tertiary care hospital in Maharashtra, India
}

Sanjeevani Ambekar ${ }^{1}$, Dhiraj Badale ${ }^{1}$, Dileep Kadam², Sonali Salvi ${ }^{2}$ 'Department of Ophthalmology, B. J. Government Medical College, Pune, India; ${ }^{2}$ Department of Medicine, B. J. Government Medical College, Pune, India

\begin{abstract}
Purpose: We conducted the study to observe the change in infection patterns with the introduction of highly active antiretroviral therapy (HAART) and correlation of CD4 count with various ocular manifestations of acquired immune deficiency syndrome (AIDS).

Design: This was a prospective observational cohort study.

Methods: The study was conducted at a tertiary care teaching institute with established antiretroviral therapy (ART) centre. A total of 240 eyes of 120 ART-naive patients were enrolled. Ocular manifestations of these patients were observed and followed up for six months for any change with HAART.

Results: Out of 240 eyes, 24 showed ocular involvement (10\%), of which human immunodeficiency virus (HIV) microangiopathy and molluscum contagiosum were most common. Out of the four cases of HIV microangiopathy, two cases demonstrated complete resolution after six months of ART. Only one of three cases of cytomegalovirus (CMV) retinitis showed healing after six months of ART.

Conclusions: Vision-threatening CMV retinitis and herpes zoster ophthalmicus can improve if specific treatment is initiated promptly. There is direct correlation between CD4 count, ocular manifestation, and prognosis of the patients; $33.33 \%$ of patients showed improvement in ophthalmic manifestations after HAART during a follow-up period of 6 months.
\end{abstract}

Keywords: antiretroviral therapy, CD4 lymphocyte count, CMV retinitis, herpes zoster ophthalmicus, HIV infection, HIV microangiopathy

\section{Introduction}

India is on the verge of being the country with the largest number of individuals living with human immunodeficiency virus (HIV)-acquired immune deficiency syndrome (AIDS). The total number of people living with HIV (PLHIV) in India was estimated at 2.117 million (1.711-2.649 million) in the year 2015. ${ }^{1}$ Ocular lesions are also on the rise as the number of HIV-infected individuals is increasing.

Correspondence: Dr. Sonali Salvi, Department of Medicine, B. J. Government Medical College, Pune 411001, India.

E-mail: sonalionly@gmail.com 
Ocular lesions were first reported in India in 1995 at Sankara Nethralaya, Chennai. The lifetime cumulative risk of developing at least one abnormal ocular lesion for a PLHIV ranges from $52 \%$ to $100 \%$ in various studies. ${ }^{2}$ The epidemiological pattern of the disease in developed countries is different from that in developing countries. With the development of highly active antiretroviral therapy (HAART) in 1998, we witnessed a delay in illness and death, as well as a change in the pattern of ocular manifestations. The incidence of opportunistic ocularinfections causing retinitis has dramatically decreased, and clinicians should be aware of changes in the clinical manifestations of HIV. Pune and Mumbai are cosmopolitan cities with rising number of HIV-infected patients. At Pune, we run a well-equipped antiretroviral therapy (ART) plus centre, which has helped us in managing patients effectively. ${ }^{4}$

\section{Materials and methods}

The study was conducted at a tertiary eye care teaching institute from December 2008 to April 2011. Ethical approval was obtained from the ethics committee of our institute. Detailed evaluation of any ocular morbidity was conducted in 240 eyes of 120 HIV-naive patients who attended the ART centre of the institute after obtaining written consent from them. All patients underwent detailed history-taking which included World Health Organization clinical stage, CD4 count, and ocular symptoms at presentation.

A complete ophthalmological examination was performed including visual acuity examination, direct and indirect ophthalmoscopy and slit lamp microscopy, fundus fluorescein angiography, fundus photography, and B scan.

\section{Inclusion criteria}

1. Drug-naive patients diagnosed as having HIV infection by enzyme-linked immunosorbent assay test at the Integrated Counselling and Testing Centre.

2. Patients who are ART eligible as per National AIDS Control Organization criteria.

\section{Exclusion criteria}

1. Patients with pre-existing diabetic or hypertensive retinopathy.

2. Patients initiated on ART from private centres or patients who were exposed to ART drugs at any point of time.

3. Patients on ART who were lost to follow-up during the study.

Patients were followed up for six months on a monthly basis. CD4 count and ocular manifestations were compared using paired t-test and chi-square test. 


\section{Observations and results}

The age of the population included in the study ranged ffrom 2 to 70 years. Most patients fell (62.5\%) within 21 to 40 years of age. Males predominated in the 120 patients, of which 24 had ocular involvement. The mean CD4 count pre-HAART was 140; post-HAART was 221.

We observed that low CD4 count patients $(<100)$ presented more commonly with severe vision-threatening manifestations in the pre-HAART group (cytomegalovirus [CMV] retinitis, HIV retinopathy, herpes zoster ophthalmicus [HZO]). Some ocular manifestations are shown in Figures 1A, B and 2.

Molluscum contagiosum and HIV microangiopathy were the most common presentations. Patients who had received ART for more than two months showed a reduction in infection rates, although statistically insignificant.

A.

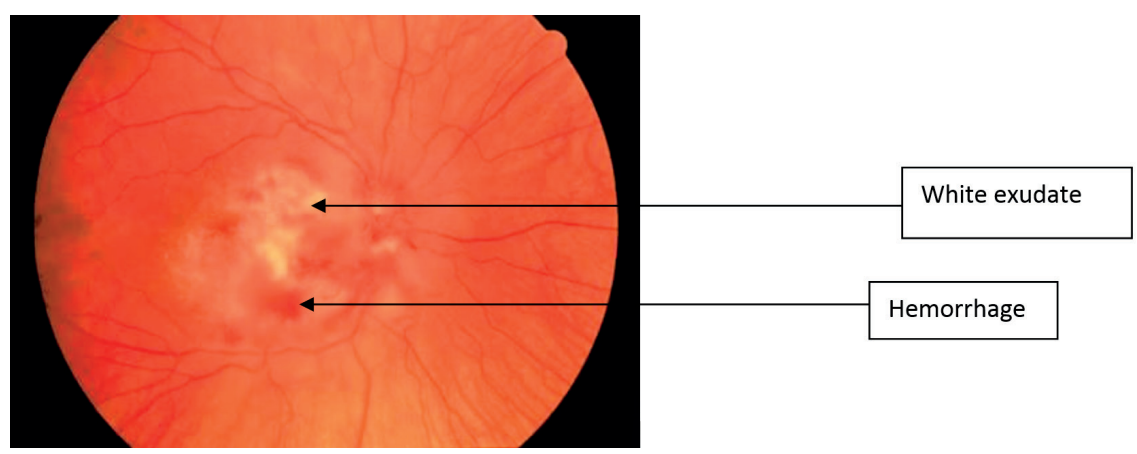

B.

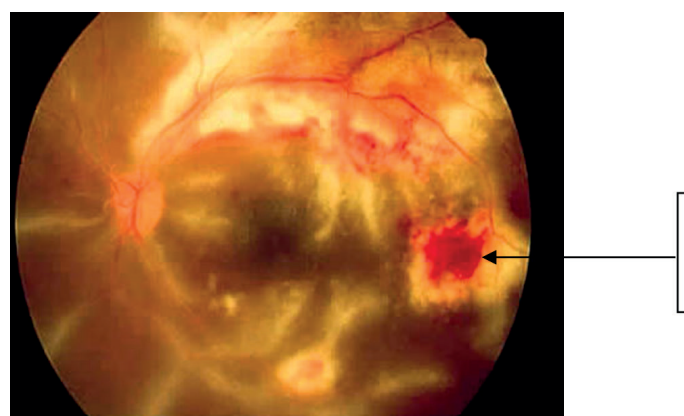

Fig. 1. Fundus photograph in case of CMV retinitis. 
Table 1. Comparison of ocular manifestations in AIDS

\begin{tabular}{|l|l|l|}
\hline Manifestation & Pre-ART (n=120) & Follow-up (n= 105) \\
\hline HIV microangiopathy & $5(4.17 \%)$ & $3(2.85 \%)$ \\
\hline Molluscum contagiosum & $4(3.33 \%)$ & $2(1.90 \%)$ \\
\hline CMV retinitis & $3(2.5 \%)$ & $2(1.90 \%)$ \\
\hline Keratoconjunctivitis sicca & $3(2.5 \%)$ & $2(1.90 \%)$ \\
\hline HZO & $2(1.67 \%)$ & $1(0.95 \%)$ \\
\hline Orbital cellulitis & $2(1.67 \%)$ & 0 \\
\hline Fungal ulcer & $1(0.83 \%)$ & $1(0.95 \%)$ \\
\hline Blepharitis & $1(0.83 \%)$ & 0 \\
\hline Conjunctivitis & $1(0.83 \%)$ & $1(0.95 \%)$ \\
\hline Neuro-ophthalmic signs & $1(0.83 \%)$ & 0 \\
\hline Choroiditis & $1(0.83 \%)$ & 0 \\
\hline Vitritis & 0 & $1(0.95 \%)$ \\
\hline Immune recovery uveitis & 0 & $1(0.95 \%)$ \\
\hline Drug reaction & 0 & $1(0.95 \%)$ \\
\hline Stevens-Johnson syndrome & 0 & $(15.23 \%)$ \\
\hline Any ophthalmic manifestation & $24 \%)$ & \\
\hline
\end{tabular}

\section{Association between CD4 count and ocular manifestation at presentation}

Tables 1 and 2 summarize our results. Molluscum contagiosum was observed in four cases and all had CD4 ranging between 100 and 250. HIV retinopathy and $\mathrm{HZO}$ were noted in patients with CD4 below 100. CMV retinitis was evident in cases with CD4 $<50$. CD4 count improved after initiation of ART. In half the cases of HIV microangiopathy, fundoscopic changes were normalized.

\section{Discussion}

Our study described the ocular manifestations in patients with HIV-AIDS and the change in the pattern of the disease with HAART. When the gender distribution of study cases is taken into account, a male preponderance was noted. In their study in Western India, Shah et al. have also reported a greater number of male patients 


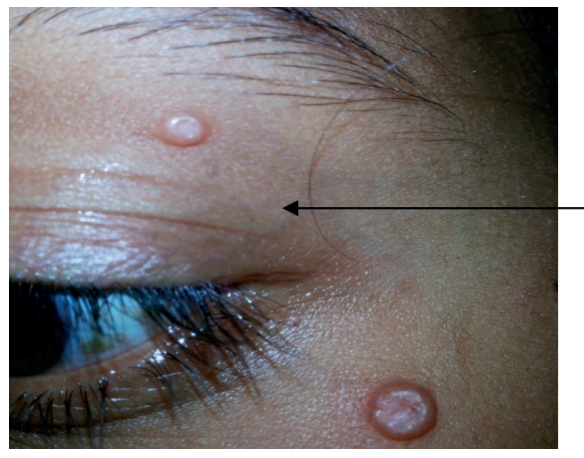

Well defined centrally umbilicated lesion on eyelid

Fig. 2. Molluscum contagiosum.

Table 2. Pre- and post-ART manifestations.

\begin{tabular}{|l|l|l|l|l|}
\hline \multirow{2}{*}{$\begin{array}{l}\text { SI. } \\
\text { No. }\end{array}$} & \multicolumn{2}{|l|}{ At the time of screening } & \multicolumn{2}{l|}{ On follow-up } \\
\cline { 2 - 5 } & CD4 & Ophthalmic manifestation & CD4 & Ophthalmic manifestation \\
\hline 1. & 69 & HIV microangiopathy & 244 & HIV microangiopathy \\
\hline 2. & 22 & $\begin{array}{l}\text { HZO } \\
\text { Dendritic ulcer }\end{array}$ & 66 & Keratitis \\
\hline 3. & 34 & CMV retinitis & 56 & Healed \\
\hline 4. & 82 & HIV microangiopathy & 99 & Normal \\
\hline 5. & 60 & HIV microangiopathy & 123 & Normal \\
\hline 6. & 58 & HIV microangiopathy & 68 & HIV microangiopathy \\
\hline 7. & 141 & Normal & 313 & Immune reconstitution uveitis \\
\hline 8. & 64 & Keratoconjunctivitis sicca & 190 & Keratoconjunctivitis sicca \\
\hline 9. & 44 & Keratoconjunctivitis sicca & Death & $\begin{array}{l}\text { Keratoconjunctivitis sicca } \\
+\end{array}$ \\
\hline 10. & 184 & HIV microangiopathy & 196 & HIV microangiopathy \\
\hline 11. & 115 & Orbital cellulitis & & Death \\
\hline 12. & 130 & Fungal ulcer & 304 & Healing fungal ulcer \\
\hline 13. & 139 & Keratoconjunctivitis sicca & 296 & Keratoconjunctivitis sicca \\
\hline 14. & 76 & HZO & - & Death \\
\hline 15. & 33 & CMV retinitis & 40 & CMV retinitis \\
\hline
\end{tabular}


with ocular infection. The difference between male and female number of cases could be due to increased prevalence of HIV infection in males. Secondly, females are deprived of screening modalities due to socioeconomic factors.

We recorded the maximum age of study patients to be 70 years and minimum age to be 2 years. The mean age was 33.4 years and median age was 35 years. Most cases (87.5\%) fell in the group between 20 and 50 years of age. Of the total 120 cases, 73 (60.8\%) were male and 47 (39.2\%) were female.

Biswas et al. concluded that the cumulative risk of at least one abnormal ocular lesion developing in HIV-infected patients is $52-100 \%$. It was also pointed out that $40-45 \%$ of HIV-infected patients in India have at least one ophthalmic manifestation when examined by the ophthalmologist. Cunningham and Margolis reported that $70-80 \%$ of HIV-infected patients had ophthalmic disease at some time during their lifetime. Table 3 compares the prevalence of ocular manifestations in our study with various other studies.

The prevalence of ocular manifestations is certainly on a declining trend owing to the rise in patients on ART and widespread availability of antiretroviral drugs through public health systems. Molluscum contagiosum and HIV microangiopathy were the most common ocular findings in the anterior segment, while CMV retinitis was the most common finding in the posterior segment. HIV microangiopathy showed significant response to HAART.

The mean CD4 count in the pre-HAART group was 140, whereas in the post-HAART group it was 224, which was statistically highly significant $(p<0.001$ by paired t-test). It proves beyond doubt that HAART is playing a major role by increasing the CD4 count, and thus, life expectancy. All three cases of CMV retinitis were observed in patients with CD4 count $<50$. Herpes zoster and HIV retinopathy occurred at CD4 count of less than 100. Only one case of immune reconstitution uveitis was noted in a patient from the post-ART group. It responded well to glucocorticoid therapy. In this patient, there was a rise in CD4 count from 141 to 313. Ocular lesions were observed in 24 patients in the pre-HAART group and 16 in the post-HAART group. In patients with ocular lesions, the median CD4 was 70 before initiation of HAART and 156.5 after initiation of HAART. This finding was highly significant statistically ( $p=0.006$ by paired $t$-test), emphasizing the pivotal role of HAART in reducing ocular morbidity and improving the quality of life.

Table 3. Prevalence of ocular manifestations in the present study with other studies

\begin{tabular}{|l|l|l|l|l|l|l|}
\hline Manifestation & $\begin{array}{l}\text { Holland } \\
\text { et al. }\end{array}$ & $\begin{array}{l}\text { Khadem } \\
\text { et al. }\end{array}$ & $\begin{array}{l}\text { Jabs } \\
\text { et al. }\end{array}$ & $\begin{array}{l}\text { Lim } \\
\text { et al. }\end{array}$ & $\begin{array}{l}\text { Kestelyn } \\
\text { et al. }\end{array}$ & Our study \\
\hline Sample size & 30 & 08 & 200 & 118 & 20 & 120 \\
\hline Ocular involvement & $63 \%$ & $50 \%$ & $25 \%$ & $37 \%$ & $55 \%$ & $20 \%$ \\
\hline
\end{tabular}


In CMV infection, early retinitis was seen as small, white perivascular retinal infiltrates or dot-blot haemorrhages. The classic lesion is a hemorrhagic necrotizing retinitis that follows the retinal vasculature. Fluffy retinal infiltrates and necrosis are usually associated with scattered hemorrhages ("scrambled eggs and ketchup" appearance) (Fig. 1A and B).

Twenty-four of 120 patients in the pre-ART group had ocular manifestations, while 16 of 105 patients in the post-ART group had ocular manifestations. In the post-ART group, the ocular manifestations decreased and the types of manifestations were different, although not clinically significant. CMV retinitis and keratoconjunctivitis sicca, which have permanent sequelae, were counted in both groups, as this is a follow-up study. ${ }^{12,13}$ Thus, prevention of ocular scar formation is of great relevance. ART initiation has been pivotal in the overall reduction of opportunistic infections. ${ }^{14,15}$

\section{Conclusions}

The prevalence of ocular manifestations decreased in the post-HAART group. Molluscum contagiosum and HIV microangiopathy in the anterior segment and CMV retinitis in the posterior segment were the most common presentations in the pre-HAART group, while Stevens-Johnson syndrome and immune recovery uveitis were specific to the post-HAART group. On comparing ocular manifestations in the pre-and post-HAART group, it was observed that the severity of ocular disease significantly declined in the post-HAART group. To conclude, availability of HAART treatment, screening from various specialties and experts through crossreference after enrolment are necessary to prevent disastrous complications of the disease. As far as ocular manifestations are concerned, early diagnosis and follow-up will help the patient have a better visual prognosis and prevent vision-threatening complications.

\section{References}

1. Annual report 2015-2016, National AIDS Control Organization.

2. Jabs DA. Ocular manifestations of HIV infection. Trans Am Ophthalmol Soc. 1995;93:623-683.

3. Conway MD, Tong P, Olk RJ. Branch retinal artery occlusion (BRAO) combined with branch retinal vein occlusion (BRVO) and optic disc neovascularization associated with HIV and CMV retinitis. Int Ophthalmol. 1996;19:249-252.

4. Friedman SM, Margo CE. Bilateral central retinal vein occlusions in a patient with acquired immunodeficiency syndrome: Clinico-pathologic correlations. Arch Ophthalmol. 1995;113:1184-1188.

5. Biswas J, Madhavan HN, George AE, Kumarasamy N, Solomon S. Ocular lesions associated with HIV infection in India: a series of 100 consecutive patients evaluated at a referral center. Am J Ophthalmol. 2000;129:9-15.

6. Cunningham ET, Margolis TP. Ocular manifestations of HIV infection. N Engl J Med. 1998;339: 236-244. 
7. Hodge WG, Seif SR, Margolis TP. Ocular opportunistic infection incidences among patients who are HIV positive compared to patients who are HIV negative. Ophthalmology. 1998;105:895-900.

8. Ali R, Kim JY, Henderson BA. Adnexal and anterior segment manifestations of HIV-AIDS. Int Ophthalmol Clin. 2007;47:15-32.

9. Meyer D. Eye signs that alert the clinician to a diagnosis of AIDS. SADJ. 2005;60:386-387.

10. Kahraman G, Krepler K, Franz C, et al. Seven years of ART impact on ophthalmic management of HIV-infected patients. Ocul Immunol Inflamm. 2005;13:213-218.

11. Zaal MJ, Volker-Dieben HJ, Wienesen M, D'Amaro J, Kijlstra A. Longitudinal analysis of varicellazoster virus DNA on the ocular surface associated with herpes zoster ophthalmicus. Am J Ophthalmol. 2001;131:25-29.

12. Mesaric B, Lisic M, Kniewald T, Ugrinovic N, Begovac J. Ocular manifestations in patients with human immunodeficiency virus infection before and after the introduction of highly active antiretroviral therapy. Lijec Vjesn. 2005;127:123-128.

13. Arruda RF, Muccioli C, Belfort R Jr. Ophthalmological findings in HIV infected patients in the post-ART (Highly Active Anti-retroviral Therapy) era, compared to the pre-ART era. Rev Assoc Med Bras. 2004;50:148-152.

14. Sudharshan S, Kaleemunnisha S, Banu AA, et al. Ocular lesions in 1,000 consecutive HIV-positive patients in India: a long-term study. J Ophthalmic Inflamm Infect. 2013;3:2.

15. Pathai S, Deshpande A, Gilbert C, Lawn SD. Prevalence of HIV-associated ophthalmic disease among patients enrolling for antiretroviral treatment in India: a cross-sectional Study. BMC Infect Dis. 2009;9:158. 